\title{
Rancang Bangun Inverter Mengubah Arus Listrik DC ke AC Berbasis Arduino Uno
}

\author{
Risky Binsar Pandapotan Simanjuntak ${ }^{1, *}$, M Safii $^{2}$, Fitri Anggraini $^{1}$, Sumarno $^{1}$, Indra Gunawan $^{1}$ \\ ${ }^{1}$ STIKOM Tunas Bangsa, Pematangsiantar, Indonesia \\ ${ }^{2}$ AMIK Tunas Bangsa, Pematangsiantar, Indonesia \\ Email: 1," riskybinsar10@gmail.com, ${ }^{2} \mathrm{~m}$. safii@ amiktunasbangsa.ac.id, ${ }^{3} \mathrm{ftranggraini850@gmail.com,}$ \\ ${ }^{4}$ sumarno@stikomtb.ac.id, 5indragunawan@ stikomtb.ac.id \\ Submitted: 10/08/2021; Accepted: 22/08/2021; Published: 31/08/2021
}

\begin{abstract}
Abstrak-Pada saat ini energy listrik sangat dibutuhkan dalam hal membantu manusia dalam melakukan kegiatan aktivitasnya baik itu dalam melakukan pekerjaan mereka sehari-hari. Dalam hal ini tidak mungkin tidak ada masalah dalam pemadaman berkala untuk menghemat sumber daya listrik yg dilakukan PLN dan membuat semua aktivitas manusia terganggu mulai dari alat-alat yg membutuhkan energy listrik tersebut. Untuk itu perlu di antisipasi dengan cara membuat alat inverter yang tujuan nya untuk membuat semua aktivitas yg di lakukan mereka menggunakan energy listrik tidak terganggu. Alat ini dibantu dengan menggunakan Arduino Uno sebagai bahan utamanya yang nantinya energy listrik DC yaitu baterai akan di ubah ke energy listrik yang biasa kita pakai yaiu energy listrik AC.
\end{abstract}

Kata Kunci: Listrik; Arduino Uno; Inverter

\begin{abstract}
At this time electrical energy is needed in terms of helping humans in carrying out their activities both in doing their daily work. In this case, it is impossible for there to be problems in periodic blackouts to save electricity resources carried out by PLN and to disrupt all human activities starting from the tools that require electrical energy. For this reason, it is necessary to anticipate by making an inverter which aims to make all the activities they do using electrical energy are not disturbed. This tool is assisted by using Arduino Uno as the main ingredient which later DC electrical energy, namely the battery, will convert electrical energy that we usually use AC electrical energy.
\end{abstract}

Keywords: Electricity; Arduino Uno; Inverter

\section{PENDAHULUAN}

Pada saat ini peralatan listrik yang digunakan pada umumnya menggunakan sumber tegangan listrik arus bolakbalik (Alternating Current/AC). Hal ini dikarenakan pembangkit listrik yang ada pada saat ini biasanya menghasilkan tegangan listrik AC. Namun beberapa tahu terakhir ini telah dikembangkan beberapa pembangkit listrik yang telah menghasilkan tegangan listrik arus searah ( Direct Current/DC ) [1].

Beberapa Faktor pendukung kemajuan elektronika saat ini tentu saja akan mempengaruhi perkembangan alat-alat elektronika yang semakin beragam. Salah satu alat yang digunakan yaitu inverter yang dapat merubah tegangan arus DC ke tegangan arus AC [2]. Inverter ini sangat sesuai sebagai penyedia listrik cadangan maupun di kendaraan atau di rumah, sebagai emergency power saat aliran arus listrik kendaraan atau yang lain padam [3]. Dalam aplikasi nya inverter ini dapat digunakan pada perangkat elektronika dan yang terpenting dapat menjadi suplai energi pada rumah di daerah terpencil. Alat ini sangat berguna terutama pada perangkat rumah tangga sangat banyak digunakan terutama pada perangkat rumah tangga sangat banyak digunakan terutama pada saat listrik padam dan kita membutuhkan sumber tegangan arus AC untuk digunakan pada lampu saat listrik padam pada malam hari dan lainnya[4].

Energi listrik yaitu sautu bentuk energi yang paling fleksibel dan murah untuk dipeprgunakan oleh semua pengguna arus listrik [5]. Oleh karena itu pemanfaatan banyak jenis sumber energy termasuk pada sumbersumber energi yang terbaru dan yang terlebih lagi di konversi ke dalam energi listrik sebelum dimanfaatkan pengguna sebagai contoh bisa kita lihat dengan energi angin, surya, dan air juga kebanyakan saat ini dimanfaatkan dengan berbagai cara terlebih terlebih dahulu yang di konversi ke dalam bentuk listrik.

Energi listrik merupakan bentuk energi yang paling fleksibel dan murah untuk dipergunakan oleh semua pihak. Oleh karena itu, pemanfaatan banyak jenis sumber energi termasuk sumber-sumber energi yang terbaru terlebih dahulu dikonversi ke dalam energi listrik sebelum dimanfaatkan oleh pengguna[6]. Sebagai contoh, energi angin, air dan juga energi surya kebanyakan dimanfaatkan dengan berbagai cara terlebih dahulu yang dikonversi ke dalam bentuk listrik [7]. Tegangan Tersimpan yang dihasilkan oleh tenaga surya memiliki kapasitas sebesar \pm 12 Volt DC. tegangan tersimpan yang dihasilkan oleh tenaga surya sebesar 12 Volt DC akan diubah menjadi arus bolak-balik AC (alternating current) sebesar 220 Volt yang dapat dimanfaatkan untuk keperluan listrik AC sesuai dengan Daya yang ditimbulkan [8].

Inverter ini sangat sesuai sebagai penyedia listrik cadangan baik di kendaraan maupun dirumah, sebagai emergency power saat aliran listrik rumah atau yang lain padam [9]. Dalam aplikasinya inverter ini dapat digunakan pada perangkat rumah tangga seperti lampu, TV, computer, kipas angin ataupun peralatan pertukangan seperti bor, gerinda dan system suplai energy pada rumah di daerah terpencil dan berbagai barang elektronik lainnya. Alat ini sangat berguna terutama pada perangkat rumah tangga sangat banyak digunakan terutama pada saat listrik padam dan kita membutuhkan sumber AC untuk digunakan pada lampu saat listrik padam pada malam hari dan lainnya. 
Journal of Computer System and Informatics (JoSYC)

Volume 2, No. 4, August 2021, Page 295-299

ISSN 2714-8912 (media online)

ISSN 2714-7150 (media cetak)

DOI 10.47065/josyc.v2i4.838

\section{METODOLOGI PENELITIAN}

\subsection{Tahapan Penelitian}

Berikut penjelasan penelitian yang dilakukan pada flowchart berikut

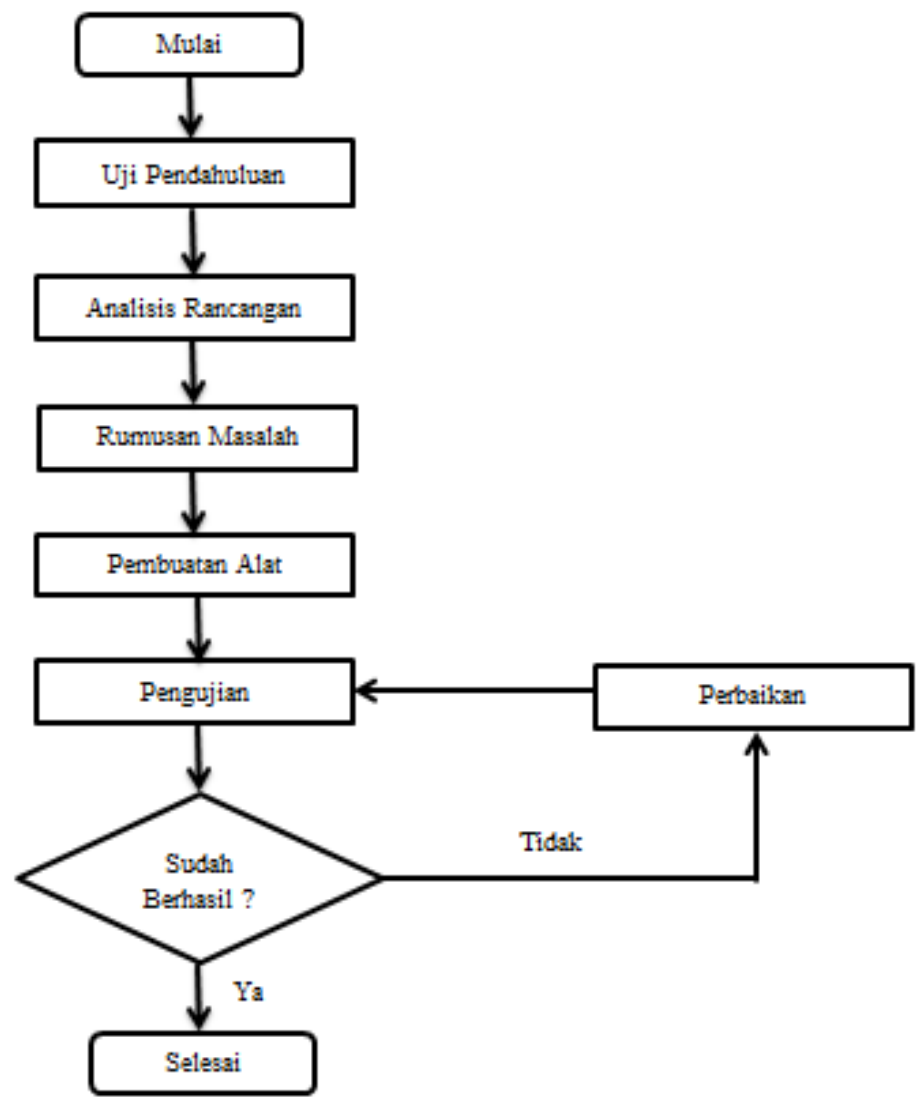

Gambar 1. Tahapan Penelitian

Berikut penjelasan flowchart penelitian yang dibuat oleh penulis pada gambar 1 dibawah ini sebagai berikut:

a. Uji Pendahuluan

Uji pendahuluan dilaksanakan untuk memperoleh suatu objek yang akan dieliti oleh peneliti. Di bagian ini diharapkan dapat memperoleh suatu permasalahan yang dapat diangkat peneliti yang terkait.

b. Analisis Rancangan

Pada tahap ini adalah bagian integral dari suatu proses sebuah penelitian yang dituangkan baik dalam bentuk tulisan atau tidak. Rancangan ini telah terformat sebelum kegiatan pengumpulan data.

c. Rumusan Masalah

Di bagian ini peneliti merumuskan atau menjabarkan dari identifikasi suatu masalah yaitu sebuah pertanyaan yang terperinci kemudian membuat solusi untuk meningkatkan hasil penelitian ini menjadi terjamin.

d. Pembuatan Alat

Di bagian ini peneliti merancang alat yang akan digunakan untuk membuat penelitian ini aman dan bermutu.

e. Pengujian

Di tahap ini peneliti melakukan pengujian alat untuk menyesuaikan alat yang digunakan untuk mengubah arus.

f. Perbaikan

Di bagian ini penulis melakukan perbaikan alat maupun yang lain apabila ada kesalahan dalam hasil penelitian tersebut.

\subsection{Spesifikasi Perangkat}

Arduino UNO merupakan sebuah papan mikrokontroler yang dikontrol penuh oleh ATmega328. Arduino UNO mempunyai 14 pin digital input/output (6 di antaranya dapat digunakan sebagai output $P W M$ ), 6 input analog, sebuah osilator Kristal $16 \mathrm{MHz}$, sebuah koneksi USB, sebuah power jack, sebuah ICSP header, dan sebuat tombol reset. Arduino UNO dapat juga memuat semua yang dibutuhkan untuk menunjang mikrokontroler, mudah menghubungkannya ke sebuah komputer dengan sebuah kabel USB atau men-supply nya dengan sebuah adaptor AC ke DC atau menggunakan sebuah baterai untuk memulainya. 
Journal of Computer System and Informatics (JoSYC)

Volume 2, No. 4, August 2021, Page 295-299

ISSN 2714-8912 (media online)

ISSN 2714-7150 (media cetak)

DOI 10.47065/josyc.v2i4.838

Tabel 1. Spesifikasi Arduino

\begin{tabular}{cc}
\hline Tegangan Operasi & $3-5 \mathrm{~V}$ \\
Tegangan Input & $5-12 \mathrm{~V}$ \\
Batas Tegangan Input & $15 \mathrm{~V}$ \\
Pin Digital I/O & 14 (dimana 6 pin output PWM) \\
Pin Analog Input & 6 \\
Arus DC per I/O pin & $40 \mathrm{~mA}$ \\
Arus DC untuk pin & $3.3 \mathrm{~V} 50 \mathrm{~mA}$ \\
Flash Memory & $32 \mathrm{~Kb}$ (Atmega328), dimana $0,5 \mathrm{~KB}$ \\
SRAM & diguanakan oleh bootloader \\
EEPROM & $2 \mathrm{~KB}$ (Atmega328) \\
Clock & $1 \mathrm{~KB}$ (Atmega 328) \\
\hline
\end{tabular}

\subsection{Spesifikasi Kebutuhan Sistem}

Dalam hal ini proses perancangan alat pengubah arus DC ke AC berbasis Arduino Uno ini diperlukannya komponen-komponen ataupun peralatan yang dibutuhkan seperti terlihat pada tabel 4.1. dibawah ini.

Tabel 2. Spesifikasi dan Kebutuhan Sistem

\begin{tabular}{cll}
\hline No & \multicolumn{1}{c}{ Komponen } & Jumlah \\
\hline 1 & Arduino Uno Atmega368 & 1 buah \\
2 & Baterai & 1 buah \\
3 & Transformator Step- $U p$ & 1 buah \\
4 & Mosfet & 4 buah \\
5 & Kabel serabut & 2 meter \\
\hline
\end{tabular}

\begin{tabular}{cll}
\hline No & \multicolumn{1}{c}{ Peralatan } & Jumlah \\
\hline 1 & Bola Lampu & 1 buah \\
2 & Solder dan Timah & 1 buah \\
3 & Multitester & 1 buah \\
\hline
\end{tabular}

\section{HASIL DAN PEMBAHASAN}

\subsection{Diagram Blok}

Blog diagram untuk perancangan alat pengubah arus listrik DC (Direct Current) ke AC (Alternatif Current) dapat dilihat pada gambar 2 dibawah ini.

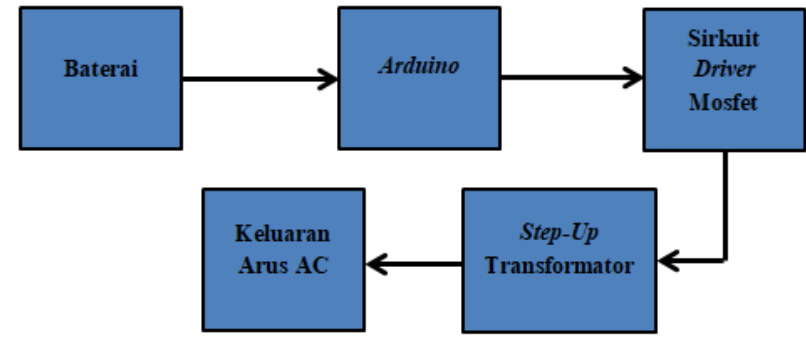

Gambar 2. Diagram Blok berikut.

Di bawah ini adalah penjelasan tentang fungsi dari rangkaian diagram blok pada gambar 2. di atas sebagai

a. Baterai ini sangat menentukan berapa lama inverter bisa digunakan. Umum nya pada sebuah UPS digunakan baterai kering dengan tegangan $12 \mathrm{~V}$ DC $7 \mathrm{AH}$. Arus dan baterai digunakan sebagai supply utama rangkaian sekaligus sebagai arus listrik yang akan dikonversikan ke arus listrik PLN.

b. Arduino berperan sebagai pembangkit gelombang PWM (Power Width Modulation)

c. Sirkuit Driver Mosfet ini sudah termasuk juga dengan osilator yang berfungsi membangkitkan multivibrator tak stabil yang di umpankan kepada penguat jenis mosfet.

d. Step-Up Transformator ini tegangan dinaikkan dengan cara mengumpankan sinyal dari mosfet. Trafo untuk inverter yang digunakan haruslah jenis CT (Center Tap).

e. Keluaran Arus AC merupakan output dari trafo inverter.

\subsection{Rancangan Alat}

Pada tahap ini penulis akan menguraikan hasil sebuah perancangan dan pembuatan alat pengubah arus DC ke AC ini menggunakan Arduino Uno. Proses perakitan ini yaitu dengan menghubungkan antar mikrokontroler Arduino Uno dengan mosfet, trafo step-up dan lainnya. Serta komponen pendukung seperti kabel jumper, papan percobaan dan lainnya. Skema rangkaian alat yang akan dirakit dapat dilihat pada gambar 3 dibawah ini. 


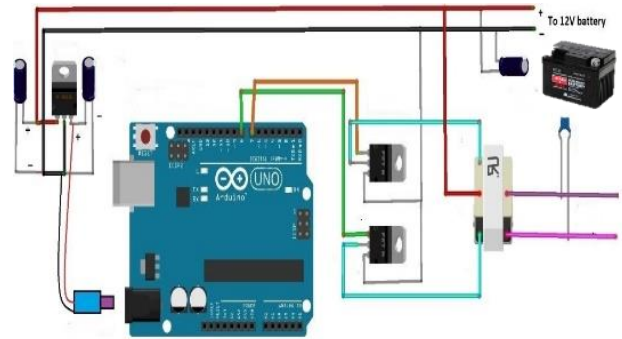

Gambar 3. Rancangan Alat

Pada skema rangkaian alat yang terlihat pada gambar 3 di atas, kemudian akan dirangkai dengan instalasi pemasangan arduino dan yang lainnya dengan menghubungkan atau mengkoneksikan pin di setiap komponen ke pin yang lainnya yang terdapat pada Arduino Uno tersebut. Berikut adalah rangkaian pin yang saling terkoneksi pada penelitian ini

1. Pin 7 dihubungkan ke kaki gate mosfet 1

2. Pin 8 dihubungkan ke kaku gate mosfet 2

3. Gnd dihubugnkan ke negatif aki

4. VCC dihubungkan dengan ke +12 volt aki

Setelah pengkoneksian setiap pin pada sebuah komponen dengan Arduino Uno, Proses selanjutnya adalah melakukan sebuah coding untuk pemberian sebuah perintah kepada Arduino dengan cara membuat kode program dengan bahasa C++ yang terletak di Software Arduino IDE [10]. Sehingga nantinya rangkaian yang telah dibuat mampu bekerja sesuai dengan penulis harapkan.

\section{a. Masukan (Input)}

Sebuah perancangan perangkat lunak pada sebuah mikrokontroler Arduino Uno ini menggunakan Software Arduino IDE yang berbasis sebuah bahasa $\mathrm{C}++$ yang telah dipermudah menggunakan library yang berfungsi untuk menulis pogram ke dalam Arduino. Setelah merancang semua alat identifikasi, penulis memasukkan perintah ke mikrokontroler Arduino Uno sesuai dengan alat yang dipakai penulis. Untuk memasukkan sebuah program ke dalam mikrokontroler Arduino Uno dibutuhkan sebuah driver USB, Arduino IDE dan sebuah Board Arduino Uno. Dan dibawah ini adalah kode program yang penulis buat untuk menjalankan perintah untuk mengubah arus listrik DC ke AC menggunakan Arduino Uno.

\section{b. Pemrosesan (Proses)}

Arduino berperan sebagai pembangkit gelombang PWM (Pulse Width Modulation). Fungsi gelombang PWM berfungsi untuk membangkitkan frequensi sekaligus mensaklar dua buah mosfet secara bergantian sehingga pada trafo step-up terjadilah suatu induksi dan induksi tersebut menghasilkan tegangan 220 AC pada kumparan primer trafo step-up saat dua buah mosfet bekerja secara bergantian.

\section{c. Keluaran (Output)}

Dalam pembuatan alat pengubah arus listrik DC ke AC berbasis Arduino Uno ini penulis menambahkan keluaran (Output) yang mengetahui apakah perangkat keras dan perangkat lunak berfungsi dengan baik. Pada penelitian ini penulis menerapkan keluaran (Output) berupa bola lampu yang menyatakan berfungsi dengan baik apabila lampu tersebut hidup dan sebaliknya. Keluaran (Output) yang digunakan penulis dapat dilihat pada gambar 4 dibawah ini.

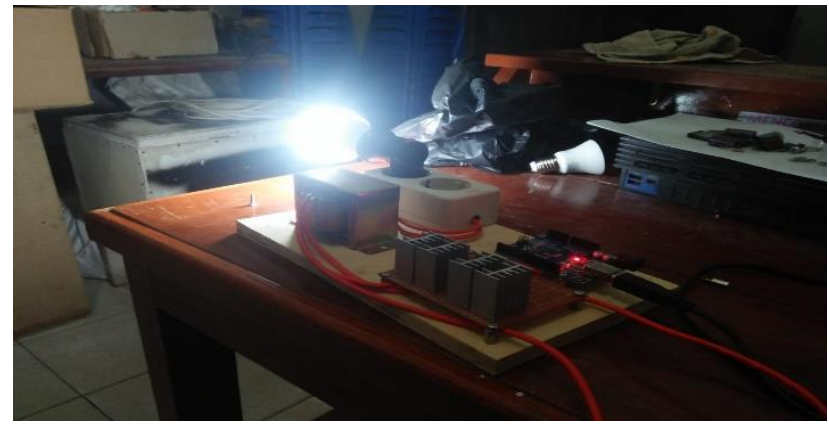

Gambar 4. Hasil Keluaran

\section{KESIMPULAN}

Berdasarkan hasil uraian dari bab-bab yang penulis buat sebelumnya serta hasil yang sudah dilakukan selama melakukan riset maka penulis pun akan mengambil keputusan sebagai berikut yaitu besar sumber daya yang 
Journal of Computer System and Informatics (JoSYC)

Volume 2, No. 4, August 2021, Page 295-299

ISSN 2714-8912 (media online)

ISSN 2714-7150 (media cetak)

DOI 10.47065/josyc.v2i4.838

dipakai penulis sangat berpengaruh terhadap daya yang dihasilkan oleh inverter kemudian Inverter yang telah dibuat mampu menghidupkan beban berupa lampu, solder (Pemanas) dengan daya yang berbeda. Jadi Arduino berperan sebagai pembangkit gelombang PWM (Pulse Width Modulation). Fungsi gelombang PWM berfungsi untuk membangkitkan frequensi sekaligus mensaklar dua buah mosfet secara bergantian sehingga pada trafo step-up terjadilah suatu induksi dan induksi tersebut menghasilkan tegangan 220 AC pada kumparan primer trafo step-up saat dua buah mosfet bekerja secara bergantian.

\section{REFERENCES}

[1] A. Azis, P. Studi, T. Elektro, F. Teknik, and U. M. Surakarta, "Rancang bangun inverter satu fasa berbasis arduino," 2019.

[2] A. Izzah, "Rancang Bangun Dan Analisis Inverter Full Bridge 1 Fasa Dengan Berbagai Variasi Input Menggunakan Spwm ( Sinusoidal Pulse Width Modulation ) Rancang Bangun Dan Analisis Inverter Full Bridge 1 Fasa Dengan Berbagai Variasi Input Menggunakan Spwm ( Sinusoida," Institute Teknologi Sepuluh November, 2017.

[3] S. Y. Panggabean, "Rancang Bangun Inverter Satu Fasa Menggunakan Teknik High Voltage Pwm ( Pulse Width Modulation )," Rancang Bangun Inverter Satu Fasa Menggunakan Teknik High Voltage PWM (Pulse Width Modulation) Subastian, vol. 11, no. 2, pp. 1-9, 2017.

[4] A. I. Maiyatullah, I. Agus, G. Permana, M. T. Dadan, N. Ramadhan, and S. Pd, "PERANCANGAN DAN IMPLEMENTASI INVERTER SEBAGAI SOLUSI ELEKTRIFIKASI WARGA DI PERUMAHAN BUAH BATU DESIGN AND IMPLEMENTATION INVERTER AS ELECTRIFICATION SOLUTION OF RESIDENT AT HOUSE BUAH BATU,” vol. 5, no. 3, pp. 2961-2969, 2019.

[5] S. Anang, "Rancang Bangun Inverter Dc Ke Ac Satu Fasa Mode Push Pull Berbasis Arduino,” 2016.

[6] Dendri, "Ubah Arus Listrik DC ke AC," pp. 1-4.

[7] P. Studi, T. Elektro, F. Teknik, and U. M. Semarang, "Jurnal tugas akhir analisa beban arus pada inverter dan trafo pada waktu pemakaian dan pengisisan aki," pp. 1-16, 2017.

[8] P. Studi, T. Elektro, J. T. Elektro, F. Sains, D. A. N. Teknologi, and U. S. Dharma, "Tugas Akhir Inverter Dengan Tegangan Masukan 12V Dc Dan Tegangan Keluaran Ac Dengan Final Project Inverter With 12 V Dc Input Voltage and Ac Output Voltage With Adjustable," 2019.

[9] D. Wandri, Waskito, and Purwantono, "PENGARUH ARUS AC DAN DC TERHADAP HASIL PENGELASAN," Carbohydrate Polymers, vol. 17, no. 1, pp. 1-13, 2016.

[10] A. J. Maabuat et al., "Perancangan Proteksi Inverter Berbasis Arduino Uno," Jurnal Teknik Elektro dan Komputer, vol. 9, no. 1, pp. 39-48, 2020. 